\title{
2012 Olympic Games Decision Making Technologies for Taekwondo Competition
}

\author{
Rene Leveaux
}

School of Systems, Management \& Leadership, University of Technology, Sydney, Australia

\begin{abstract}
Leading up to the 2012 Olympic Games the demands for transparency and correctness in referee decision making in the sport of taekwondo increased dramatically to the extent where differing technologies were implemented for the first time at the Olympic level in London. This post Olympic research examines the impacts of those technologies on one sector of the sport's stakeholders - referees. The study was conducted through discussion groups and interviews with elite level international referees $(n=31)$. The findings present that via the diligent use and application of the technologies, provided mechanisms to greatly improve the correctness of decisions by being an effective aid to the referee's decision making process, which contributed to the success of the event. Further it can be seen that with the implementation and use of these technologies, competition can now be provided on a fairer platform, in turn leading to a greater improvement in player performance and providing a more attractive competition. These findings provide a platform for further studies including trials utilizing more advanced technologies to further increase the transparency and correctness of referee decision making.
\end{abstract}

Keywords: Decision making, information technology, competition.

\section{Introduction}

The sport of Taekwondo has origins reportedly dated back over 2000 years, where the Korean martial arts developed in 3 main kingdoms - Koguryo (37 BC - 668 AD), Silla (57 BC-918 AD) and Paekche (18 BC-660 AD) (Capener and Kim 2000). Currently there are two world bodies - the International Taekwondo Federation (ITF) and the World Taekwondo Federation (WTF), with the latter recognized as the governing body by the International Olympic Committee (IOC). The first World Championships were held in Korea in 1973 with participants from 19 countries (WTF, 2006). The sport made its first appearance at the Olympic Games in the 1988 Seoul and 1992 Barcelona Olympic Games as a demonstration sport. Since being a full medal sport at the 2000 Sydney Olympic Games, the sport continues to grow rapidly, with the WTF, in July 2011, admitting its $200^{\text {th }}$ member country. This now places the sport amongst the top 10 of International Sports Federations. The sport is currently contested globally at the amateur, semiprofessional and Olympic levels (WTF, 2011).

Since the sport's first World Championships, there has been continual changes surrounding most aspects of the game. Primarily focused to address the demands to ensure the sport is, not only attractive to spectators, but providing transparency in the decision making of the match officials. This has been achieved by ensuring the sport embraces the advances in technology.

The transformations during this period, range from the duration of rounds, the uses of electronic scoring protectors, the introduction of live video review during matches, the numbers of match refereeing officials, the point scoring criteria, the competition area dimensions, as well as medium, provided that original work is properly cited. Contact author: Rene Leveaux E-mail: rene.leveaux@uts.edu.au 
competition rule changes and modifications to their interpretations to be used by the refereeing officials.

The International Fair Play Committee (2007) reports that the referee is required to evaluate the important characteristic of an event or situation, and present the appropriate and correct decision in about 1 second. Mascarenhas (2005) highlighted that referees have to respond almost immediately to events in a game that unfolds dynamically and which may have many nuances, ambiguities and uncertainties. In general, the elite level referee is required to make rapid decisions while also considering numerous sources of information.

\section{Research Method}

The study was conducted through discussion groups and a series of interviews. The advantage of doing a qualitative research was that it allowed greater understandings of the interviewees' personal constructs and experiences. All participants in the study were fully informed and voluntarily consented to their involvement. Participants were also free to withdraw from the research without giving reason or justifying their decision at any time, if they so wished.

The sport of Taekwondo was indentified and examined due to its recent and increasing introduction of considerable IT related decision making technologies to minimise the likelihood of officiating errors, validation of scoring and the immediate correction of errors, which were also to be used for the first time at the Olympic level at the 2012 London Olympic Games.

The technologies include the use of electronic body protectors ("hogue"), which automatically record scores according to contact and preset criteria, or by scoring systems where points are sighted by judges and recorded via electronic hand devices. These are either run as separate entities or networked with game management software. These technologies, along with instant video analysis, have now been formally adopted and are mandatory at World Championship level and were also used in the 2012 Olympic qualification events.

\section{Interviews}

Two pre-interview discussions $(n=3, n=5)$ were held prior to the Olympic Games. As suggested by Patton (1990) this allows other related topics to emerge. From the discussions, a general interview script was developed based on issues derived from comments and points raised. All the participants had refereed Taekwondo up to and including international competition. McCracken (1998) discusses how interviews can draw on the past as well as the present to extract a deeper understanding of an issue than a simple survey type inquiry. Erlandson (1993) states that the use of semi-structured interviews allows the investigator to ask respondents for facts as well as gathering opinions. The same main format of questioning was employed in all interviews $(n=28)$.

The interviewed subjects were solicited through email or through chain sampling. Chain sampling "identifies cases of interest from people who know people who know people who are information-rich, that is, good examples for study, good interview subjects" (patton, 1990). All of the 31 volunteers were chosen for interview on the basis of availability, suitable experience and use of technology in their chosen sport (Taekwondo). Erlandson (1993) suggests that this technique of "purposive sampling" is preferred to random or representative sampling because the major concern of the researcher is to maximize discovery of the problem and the heterogeneous patterns that occur within the context of the particular study. Semi-structured interviews were conducted at a location that suited the interviewee and in general lasted approximately 40 minutes.

The focus of the questions centred on the views, if any, participants had to the uses of information technology and the impact of the use of the technology in relation to their individual preparation and decision 
making in Taekwondo. Any views or opinions in relation to another sport, or technologies not employed by their sport, were disregarded. Participants were also asked about their own adaptation to the use of the technologies, changes to their own practices leading up to, during and after a match. Their personal viewpoints on information technology, in relation to levels of application and introduction, what they enjoyed or did not enjoy with the use of the technology(s) employed in the sport, and what aspects they had or had not appreciated were also explored. The interviews were recorded and transcribed for analysis. Follow-up phone calls were made to six respondents where clarification or further investigation was required.

The interview transcripts were analyzed using constant comparison and analytic induction methods in order to identify and extract common themes across participants (Robinson, 1951; Lincoln and Guba, 1985). First, the data for each interviewee were reviewed and themes identified, and the themes from each were then compared and contrasted. Common themes were identified and the data reexamined with regard to these data categories.

\section{Post Interview Discussions}

The post interview discussion was held with five participants in addition to the author. All have a deep understanding of the sport and its rules and regulations, and were either directly or indirectly involved in the Olympic taekwondo competition. Four participants are actively involved in Taekwondo in Australia and one is actively involved in the sport in the United Kingdom and was directly involved in the Taekwondo competition during the London Olympic Games. All currently officiate at international competition.

Using the data drawn from the interviews, potential applications and variances of IT were identified in relation to the referee making decisions during competition. Specific or branded technology was intentionally not identified or addressed, but rather the type and applications of IT being used was discussed, and the impacts from the officials' perspective in the Taekwondo matches were identified.

The discussion was unstructured and free formatted. A primary general focus was on the uses and applications of information technologies to sport at the Olympic level. Discussion focused on the ability of information technology to assist referees in their decision making and ensuring correctness of their decisions. The discussion also revealed additional considerations not earlier identified in relation to perceived attitudes to the use of IT. Individual responses to the discussion were analyzed, and themes were identified, and where common themes existed the data was re-examined with regard to these data categories.

\section{Findings and Results}

There has been and is considerable emphasis and pressure by the world governing body for the development and adoption of electronic scoring mechanisms to replace the scoring functions presently performed by the judges and to adopt technologies to allow instant review of play and decisions by officials.

The sport has introduced differing levels of IT, with electronic scoring devices first used in elite level competition in 1995 and decision making technology introduced in 2009. The impacts of the technologies with referee's decision making and match management fell under either all or some of the following three categories, and are supported by comments received during the interviews and post-interview discussions.

\section{Type of Scoring Technology}

Prior to the introduction of technologies, scoring was performed by judges who recorded scores via pen and paper from each corner of the competition area. In the early 1990's Taekwondo commenced using electronic hand held scoring devices (See Table 1). These devices were used by the judges who scored points by depressing 
buttons when seeing a score. If the majority of the judges viewed the score and registered it within one second, the score was then deemed to be a legitimate score and the point was awarded to the athlete. These scores were publicised automatically via match management software.

Even with this early introduction the official's decision making and match management was being affected by the electronics.

As soon as we started using the hand held devices, I had to make sure when I was judging that I scored a point immediately, because if I missed the one second window there was a good chance the point might not have been scored; as with the paper system we had to ensure we score the point but there wasn't any real time constraint.

Decision making technologies were trialled in 2008 and introduced into the sport in 2009. They have now been mandated to be used at all major tournaments. This technology automatically scores kicking techniques to the body via the body protector (PSS - Point Scoring System) worn by the athlete. Three types of PSS protectors have been used in international competition since the technology's introduction (see Table 1).

Table 1: Types of Decision Support Technologies Used in Taekwondo

\begin{tabular}{|l|l|}
\hline \multicolumn{1}{|c|}{ Technology } & \multicolumn{1}{c|}{ Technologies Used/Trialled } \\
\hline $\begin{array}{l}\text { Hand held electronic } \\
\text { devices }\end{array}$ & $\begin{array}{l}\text { Various types } \\
\text { Records scores as identified by judges } \\
\text { Transmits either by radio frequency or via direct connection } \\
\text { to a control box }\end{array}$ \\
\hline $\begin{array}{l}\text { Adidas PSS } \\
\text { (ESM) }\end{array}$ & $\begin{array}{l}\text { Records scores using information technology } \\
\text { Operates on force } \\
\text { Transmits scores using Bluetooth technology }\end{array}$ \\
Introduced 2008 & $\begin{array}{l}\text { Development of product commenced in 1982 } \\
\text { Records scores using information technology } \\
\text { Operates under two different modes: } \\
\text { Proximity based on closing an electronic circuit, or force } \\
\text { Transmits scores using proprietary technology }\end{array}$ \\
Introduced 2009 & $\begin{array}{l}\text { Development of the product commenced in 2002 } \\
\text { Records scores using information technology } \\
\text { Identified points on a combination of proximity and force } \\
\text { First Decision Support Technology to be used in Olympic } \\
\text { Games - London 2012 }\end{array}$ \\
\hline $\begin{array}{l}\text { Daedo PSS } \\
\text { (E-Pro/TruScore) }\end{array}$ & $\begin{array}{l}\text { Allowed for instant review of referee's decision, or } \\
\text { Review of point scored/not scored } \\
\text { Provide multiple views and slow motion } \\
\text { Used in Olympic Games for first time in London 2012 }\end{array}$ \\
\hline Introduced 2010 & Video Replay
\end{tabular}

Decision making technology and video analysis software were used for the first time in Olympic Games during the recent 2012 London Olympics.

Scores for techniques to the head continue to be scored by the judges, with some techniques now requiring the judges to simultaneously press two buttons for the one technique. The technology developers are currently trialling head protectors with sensors to record scores to the head.

None of the technologies currently can identify the type of technique, and as the WTF changed the point system (see Table 2) to allow an additional point for a turning or spin technique to the body or head, the additional point for the more complex technique too is now scored by the judges. 
Table 2: Scores and the Technologies Used for the Scoring in Taekwondo

\begin{tabular}{|l|l|}
\hline Technique & Point Value and Scored by \\
\hline $\begin{array}{l}\text { Punch technique } \\
\text { to the body }\end{array}$ & $\begin{array}{l}\text { 1 point scored by the judges using hand held devices } \\
\text { Punch techniques are not permitted to the head }\end{array}$ \\
\hline $\begin{array}{l}\text { Kick technique to the body } \\
\text { (non spin) }\end{array}$ & 1 point scored by the electronic technology \\
\hline $\begin{array}{l}\text { Kick technique to the body } \\
\text { (spin or turning kick) }\end{array}$ & $\begin{array}{l}\text { 2 points - consisting of: } \\
\text { 1 point scored by the electronic technology, plus } \\
\text { 1 extra point scored by the judges using hand held devices }\end{array}$ \\
\hline $\begin{array}{l}\text { Kick technique to the head } \\
\text { (non spin) }\end{array}$ & 3 points scored by the judge using hand held devices \\
\hline $\begin{array}{l}\text { Kick technique to the head } \\
\text { (spin or turning kick) }\end{array}$ & $\begin{array}{l}\text { 4 points - consisting of: } \\
\text { 3 point scored by the judges, plus } \\
\text { 1 extra point scored by the judges using hand held devices }\end{array}$ \\
\hline
\end{tabular}

It was found that the officials had to adapt to the way the different PSS technologies worked. This was more apparent with the scoring of the additional point as the technologies handled the scoring window differently.

I'm lucky, having worked with LaJust, Adidas and Daedo. They all work differently. Especially with the extra point (for spin or turning technique), so there is a chance I can and sometimes miss the extra point when I go form one system to the other.

Some raised concern with respect to transparency of scoring. It was also noted that even though an athlete would use a legitimate technique, which may have previously been scored by the judges, it may not score unless it was executed in a specific manner unique to the information technology, as the technology requires the athletes to adapt to the type of scoring system used, for the technology to register a valid score.

It amazes me when you see a great kick and hear a huge slap noise, that the system does score it because the foot didn't land the way the technology wants it to. But I guess it's the same for both athletes and they just have to change their kicking style to what is expected by the technology.

\section{Real Time Results}

The recently introduced decision making technologies has however, increased the responsibility of the referee and judges to ensure the correctness of scoring, as scores now come automatically from two sources - the electronic scoring system and the judges via hand held electronic controllers. While the technology does pick up points that may not have been seen (or scored) via the naked eye due to the increased speed of the game and increased complexity of techniques, several of the interviewees expressed concerns of points being scored through the closing of circuitry rather than power and/or technique. Several referred to this with expressions such as "soft points".

Before the PSS (electronic scoring system) was introduced and all techniques were worth 1 point, it was easy to keep score, more so as the game was somewhat slower and more predictable and you would know if a point didn't go up. But now, it's a new ball game, with the 5 different ways points can come up and with different values, it's a lot harder ... and then throw in the "soft" points scored by technology ...

Some transparency is now provided via the display of the power levels achieved by players with kicking techniques to the body. Each weight category has a different scoring threshold, and when the kick reaches or exceeds the threshold, a point is scored. Additionally, feedback is also provided to match officials with real time data indicating the technology is correctly functioning during the match. Considerable trust has been placed in the technology, to the extent that "electronic" decisions cannot be challenged via the video review 
process. Where as any other point, say to the head or penalties may be reviewed via a coach's request.

Technology's introduction has however comes at a price, as the decisions made via the technology does not allow for the necessary flexibility of a rule's interpretation to a situation that may have been done in the past by a referee. This now has resulted in some decisions being now taken out of the referee's hands and is now applied clearly in black and white, which in turn has led to shifts and changes in the manner in which the game is played; resulting in some cases, with potentially a totally different outcome.

Interestingly some points which I felt would have been awarded by the judges due to the the technique meeting the scoring criteria, are not awarded by the technology.

\section{Support Technologies}

The video system had been introduced to allow for transparency in decision making and a speedy resolution to potential protest situations. At the 2012 Olympic Games, coaches were given one video request for the elimination rounds and if they had used their quota were allocated one more foe the medal matches.

When a coach requested a video review, the actual request was announced to the audience and same video replay was displayed in real time to the audience as the video jury would be making their decision.

Prior to the introduction of video review, the only avenue for dispute resolution was via a formal protest process on the completion of a match, which by nature took considerable time and often incurred delays in competition.

In the sport of Taekwondo, video and video analysis software is used by a review jury during the match to review a request made by a coach in relation to either a score or a referee's decision relating to a penalty. Basically a video review request may be on any decision or infraction, except points scored by the electronic scoring systems.
The requested review may be made for either the coach's player or the opposing player. A request must be made within 5 seconds from the occurrence of the incident to be reviewed.

Neither the referee nor the judges have access to video review during the match, for them to ensure the correctness of their decision(s).

The post-interview discussion group addressed the uses of video review in depth. Most felt that video was not necessarily a win/win situation, as a match is very dynamic and to have a facility where a coach stops the flow of the match to check on a decision or potential decision, could be tactically disruptive.

It really annoys me when a coach asks for a video review and it's for nothing. In several cases, it's being used to break up the flow of the match or to get his player out of a jam like going out of bounds. In some cases coaches are using the video as a tactically to deny their player's opponent the advantage.

The current video review process has achieved the goal of speedily addressing protests and has actually afforded a broader protest platform for coaches. Video review requests must be resolved in 2 minutes (WTF, 2011), however video review judges for the Olympic Games were set an unofficial goal of 13 seconds to resolve a request.

There was general confirmation of the importance of the use of the video system and the acceptance of video technology systems being employed. However, some concern was expressed in relation to the number and placement of the video cameras, especially as judges were making decisions based on the individual judge's view from differing angles to the video camera. There was some fear that the judges in this light may be viewed as not being competent in their roles, while the referees also expressed similar concerns relating to infringements committed on the referee's blind side, and subsequently may not be visible to the referee, would also reflect poorly. 
The video system is good to make sure that the correct things happen. But, when things happen on my blind side or I make a decision fairly and then have to reverse it because of the video angle, which can be wrong, it really annoys me and I know it annoys the player who it has just happened to.

\section{Discussion}

The discussion groups and the interviewees felt the introduced technology definitely enhanced correct decisions and provided improved transparency, to such extent the president of the World Taekwondo Federation proclaimed that the 2012 London Olympics were the best and fairest of all the Olympic Taekwondo competitions. It has also been generally considered that the application of the technologies to ensure fairness and to meet spectator expectations was not only affecting the way and strategies of play needed to win, but the technologies are driving the changes to the sport. Subsequently this is also shifting (and increasing) the skill sets required to referee in the sport.

Interestingly, even though they were in favour of electronic scoring technologies, all felt that the sport still needed to be officiated by a referee(s) - and not solely by IT - due to the myriad of situations and nuances that occur in competition which ultimately could not be interpreted purely by technology.

The participants identified their roles have increased, adding an additional learning curve and adaptation process to be met by elite referees. Their individual success is now also dependent on their understanding the roles and functions of the technology being used, the appropriate application of guidelines or regulations for its use, and all of those officiating in a match using the information technology constructively.

It initially it took a bit of time to get used to (new technology). The different systems work differently and score differently. It was a bit frustrating but now I am used to it, I can adapt quickly - whereas when each different system first came in, it was a whole new game. The game continues to change because of the changes in the protectors and I have to change my understandings of the technology to keep up.

It was also noted that external factors, such as exposure to the new technologies, training/education with the new technology, funds to acquire the information technology, etc, all play a major part. Unfortunately with the introduction of IT the gap between the wealthier and the poorer countries appears to have been widened, and the ability to be competitive at the elite level is now requiring access to considerably more resources due to the introduction of information technology.

\section{Conclusion}

This work shows that differing information technologies have been introduced into the sport with differing levels of success and is now reasonably well received as part of the game. In most instances, information technology promotes a more attractive sport for both the spectators and the players due to the contest being determined more transparently and on the athletic ability and performance of the participants, with minimal human (referee) intervention in the scoring process.

While the introduction and adoption of information technologies into the sport was cautiously and very sceptically received by refereeing officials initially, it is now accepted at the elite level and has provided both an innovative and effective support mechanism to provide the platform for both increased transparency and correctness of referee's and judge's decision making in the game. Now most referees feel that the decision making technologies are for the betterment of the game.

It has been recognized, to some degree, the technologies have also acted as transformers of the sport, necessitating the dimensions and skill sets of elite level refereeing officials to have broadened and also now requiring adaptability to the varying technologies. 
The applications of the technologies can now be attributed to the success of the Taekwondo competition at the 2012 Olympic Games, and subsequently assist the sport in confirming its position as an Olympic sport.

\section{References}

Capener, S. D. \& Kim, H. E. (ed.) (2000). Taekwondo: The Spirit of Korea (portions of). 2000 Retrieved 16 December 2011, from

http://www.martialartsresource.com/ano nftp/pub/the_dojang/digests/spirit.html,

Erlandson, D. A. (1993). Doing a Naturalistic Inquiry: A Guide to Methods, Newbury Park, CA.

Guba, E. G. \& Lincoln, Y. S. (1985). Naturalistic Inquiry. Newbury Park, CA: Sage.

IOC. (2007). The International Committee for Fair Play. 2007. Retrieved 28 March 2010, from http://www.olympic.org/uk/organisation/ actions/index_uk.asp,

Mascarenhas, D. R. D., Collins, D. \& Mortimer, P. (2005). 'The Accuracy, Agreement and Coherence of DecisionMaking in Rugby Union Officials,' Journal of Sport Behaviour, 28: 254.

McCraken, G. (1988). The Long Interview, Newbury Park, CA.

National Association of Sports Officials (NASO). Sports Officials Code of Ethics. 2007 Retrieved 28 March 2010, from http://www.naso.org/benefits/ethics.htm,

Patton, M. Q. (1990). 'Qualitative Evaluation and Research Methods (2nd ed.),' Thousand Oaks, CA: Sage.

Robinsonm W. S. (1951). "The Logical Structure of Analytical Induction," American Sociological Review, 16: 812-818.

World Taekwondo Federation. Competition Rules \& Interpretation. 2011. Retrieved 18 January 2012, http://www.wtf.org/wtf_eng/site/rules/co mpetition.html,

World Taekwondo Federation. History. 2006 Retrieved 28 Febuary 2012, from http://www.wtf.org/wtf_eng/site/about_w tf/history.html, 